\title{
Cost-effectiveness of insulin degludec versus insulin glargine U100 in adults with type 1 and type 2 diabetes mellitus in Bulgaria
}

Monika Russel-Szymczyk ${ }^{1 *}$, Vasil Valov², Alexandra Savova ${ }^{3}$ and Manoela Manova ${ }^{3}$

\begin{abstract}
Background: This analysis evaluates the cost-effectiveness of insulin degludec (degludec) versus biosimilar insulin glargine U100 (glargine U100) in patients with type 1 (T1DM) and type 2 diabetes mellitus (T2DM) in Bulgaria.

Methods: A simple, short-term model was used to compare the treatment costs and outcomes associated with hypoglycaemic events with degludec versus glargine U100 in patients with T1DM and T2DM from the perspective of the Bulgarian National Health Insurance Fund. Cost-effectiveness was analysed over a 1-year time horizon using data from clinical trials. The incremental cost-effectiveness ratio (ICER) was the main outcome measure.

Results: In Bulgaria, degludec was highly cost-effective versus glargine U100 in people with T1DM and T2DM. The ICERs were estimated to be 4493.68 BGN/quality-adjusted life year (QALY) in T1DM, 399.11 BGN/QALY in T2DM on basal oral therapy (T2DM $\mathrm{BOT}_{\mathrm{T}}$ ) and 7365.22 BGN/QALY in T2DM on basal bolus therapy (T2DM $\left.\mathrm{B} / \mathrm{B}\right)$, which are below the cost-effectiveness threshold of 39,619 BGN in Bulgaria. Degludec was associated with higher insulin costs in all three patient groups; however, savings from a reduction in hypoglycaemic events with degludec versus glargine U100 partially offset these costs. Sensitivity analysis demonstrated that the results were robust and largely insensitive to variations in input parameters. At a willingness-to-pay threshold of 39,619 BGN/QALY, the probability of degludec being cost-effective versus glargine U100 was 60.0\% in T1DM, 99.4\% in T2DM $\mathrm{BOT}_{\mathrm{BO}}$ and $91.3 \%$ in T2DM $\mathrm{B} / \mathrm{B}$.

Conclusion: Degludec is a cost-effective alternative to biosimilar glargine U100 for patients with T1DM and T2DM in Bulgaria. Degludec could be of particular benefit to those patients suffering recurrent hypoglycaemia and those who require additional flexibility in the dosing of insulin.
\end{abstract}

Keywords: Cost-effectiveness, Diabetes, Hypoglycaemia, ICER, Insulin degludec, QALY

\section{Background}

The treatment of diabetes and its complications represents a major economic burden to healthcare systems worldwide. An estimated 425 people aged $20-79$ years worldwide had diabetes in 2017 with an associated healthcare expenditure of approximately $\$ 727$ billion [1]. This is projected to reach $\$ 776$ billion by 2045 . The mean diabetesrelated expenditure in Bulgaria per person with diabetes is $\$ 798$ per year [1]. The treatment of diabetes-related complications, such as cardiovascular disease, retinopathy and

* Correspondence: zmns@novonordisk.com

${ }^{1}$ Novo Nordisk Pharma Sp. z o.o, Warsaw, Poland

Full list of author information is available at the end of the article neuropathy, makes up the largest part of the direct medical costs associated with diabetes care, with less than $10 \%$ spent on insulin and anti-diabetic drugs [2,3]. Diabetes is also associated with considerable indirect costs (e.g. due to absenteeism and lost productivity) [4].

The goal of diabetes treatment is to achieve good glycaemic control to prevent or delay macro- and microvascular complications and reduce cardiovascular and all-cause mortality [5, 6]. All people with type 1 diabetes (T1DM) require insulin. The Bulgarian Society of Endocrinology recommends the use of intensive insulin therapy with a basal-bolus regimen for people with T1DM [7]. Type 2 diabetes (T2DM) is a

(c) The Author(s). 2019 Open Access This article is distributed under the terms of the Creative Commons Attribution 4.0 International License (http://creativecommons.org/licenses/by/4.0/), which permits unrestricted use, distribution, and reproduction in any medium, provided you give appropriate credit to the original author(s) and the source, provide a link to the Creative Commons license, and indicate if changes were made. The Creative Commons Public Domain Dedication waiver (http://creativecommons.org/publicdomain/zero/1.0/) applies to the data made available in this article, unless otherwise stated. 
progressive disease and although glycaemic control can initially be achieved with the use of other antihyperglycaemic agents, a large proportion of people will eventually require insulin to achieve glycaemic targets [8]. The Bulgarian Society of Endocrinology guidelines recommend a patient-centred approach, and indicate that the treatment should be individually adjusted to patient age, disease progression, existing co-morbidities and preference [7]. Insulin is the most effective therapy for reducing blood sugar $[8,9]$, however, despite clear guidelines $[10,11]$, glycaemic control remains sub-optimal $\left(\mathrm{HbA}_{1 \mathrm{c}}>7 \%\right)$ in a substantial number of patients [12-15]. In Bulgaria, approximately $50 \%$ of patients with $\mathrm{T} 2 \mathrm{DM}$ in specialist care and $57 \%$ of patients in primary care have $\mathrm{HbA}_{1 \mathrm{c}} \geq 6.5 \%$, and for many patients regular testing and subsequent treatment adjustment is uncommon [16]. Insulin is often underutilised, as it is not initiated in a timely manner, titrated properly, or intensified appropriately [17, 18]. Fear of hypoglycaemia, weight gain and restrictive treatment regimens are key impediments to insulin use [19].

Insulin degludec (degludec) is a basal insulin with a duration of action of more than $42 \mathrm{~h}$, and a distinct, slow absorption mechanism, which results in a flat and stable action profile [20, 21]. Degludec has a four times lower day-to-day variability in glucose-lowering effect compared with insulin glargine (glargine) U100 and U300 [22-24]. Degludec's stable and long action profile allows for flexibility in the timing of insulin administration and allows people to advance or delay administration with no impact on short-term glycaemic control and minimal risk of hypoglycaemia [25].

A large scale clinical trial programme (BEGIN), which included more than 9000 people with T1DM and T2DM and spanned the entire treatment spectrum of insulin treatment for T1DM and T2DM, supports the efficacy and safety of degludec [26]. Based on meta-analyses, degludec mediates equivalent reductions in $\mathrm{HbA}_{1 \mathrm{c}}$ with a lower risk of hypoglycaemia compared with glargine U100 at a significantly lower total daily insulin dose in T1DM and T2DM with basal-only insulin [27, 28]. These results have been confirmed in real-world studies demonstrating better glycaemic control and fewer episodes of hypoglycaemia in patients switching from glargine U100 or other basal insulins to degludec $[29,30]$.

With the ever-increasing constraints on the healthcare budget, new interventions should represent good value for money. Understanding both the economic and clinical impact of an intervention helps decision makers determine resource use and optimal care for patients. In costeffectiveness analyses, the value of interventions is estimated by comparing the relative cost and outcomes. The relative differences are presented as incremental costeffectiveness ratio (ICER), which is the difference of costs of two interventions divided by the difference in health effects. Quality-adjusted life years (QALYs) are a measure that combines life expectancy and health-related quality of life and are an accepted measure of effectiveness [31]. Decision-makers consider the incremental cost per additional QALY gained when allocating healthcare resources, to achieve maximal economic and clinical benefits. Many countries define a financial threshold of acceptable costeffectiveness. In Bulgaria, the commonly accepted threshold is $3 x$ the gross domestic product (GDP) per capita (39, 619 BGN/QALY), in line with World Health Organization recommendations [32].

Recent cost-effectiveness analyses have demonstrated that degludec is cost-effective versus glargine U100 (Lantus $\left.^{\circ}\right)$ in the United Kingdom and Serbia [33, 34]. Biosimilar insulin glargine U100 (Abasaglar ${ }^{\circ}$ ) has recently entered the basal insulin analogue market in Bulgaria, expanding therapeutic options for patients. There are currently no head-to-head data of degludec versus Abasaglar; ; however, cost-effectiveness analyses can be conducted using available data and plausible assumptions.

The objective of this study was to assess the costeffectiveness of degludec versus biosimilar glargine U100 in the treatment of adults with T1DM and T2DM in Bulgaria from the perspective of the Bulgarian National Health Insurance Fund (NHIF).

\section{Methods \\ Model overview}

This cost-effectiveness model compared degludec with glargine U100 in three separate patient groups: T1DM using basal-bolus therapy $\left(\mathrm{T}_{1} \mathrm{DM}_{\mathrm{B} / \mathrm{B}}\right)$; T2DM using basaloral therapy $\left(\mathrm{T} 2 \mathrm{DM}_{\mathrm{BOT}}\right)$; $\mathrm{T} 2 \mathrm{DM}$ using basal-bolus therapy $\left(\mathrm{T}_{2} \mathrm{DM}_{\mathrm{B} / \mathrm{B}}\right)$. Biosimilar glargine U100 (Abasaglar ${ }^{\circ}$ ) was chosen as the most appropriate comparator in the economic analyses as glargine is the most widely used basal insulin analogue in Bulgaria and biosimilar glargine U100 serves as reference price per daily defined dose (DDD).

The analysis assumes that Abasaglar ${ }^{\circ}$ has the same efficacy and safety as originator glargine U100 (Lantus ${ }^{\circ}$ ).

For the current cost-effectiveness analysis, a simple model with a 1-year time horizon model was developed in Microsoft ${ }^{\circ}$ Excel 2010 (Microsoft Corp., Redmond, WA, US) to capture the direct medical costs associated with insulin treatment and hypoglycaemia (Fig. 1). The effectiveness (QALY) was calculated by multiplying the disutility per hypoglycaemic event by the number of events in each treatment group.

The short-term model is appropriate as the treat-totarget trial design enforces a similar level of glycaemic control across comparators and no difference in terms of glycaemic control (difference in $\mathrm{HbA}_{1 \mathrm{c}}$ ) is expected. Therefore, there is no rationale for long-term modelling based on reductions in $\mathrm{HbA}_{1 \mathrm{c}}$. Although the costeffectiveness of degludec was analysed in a short-term 


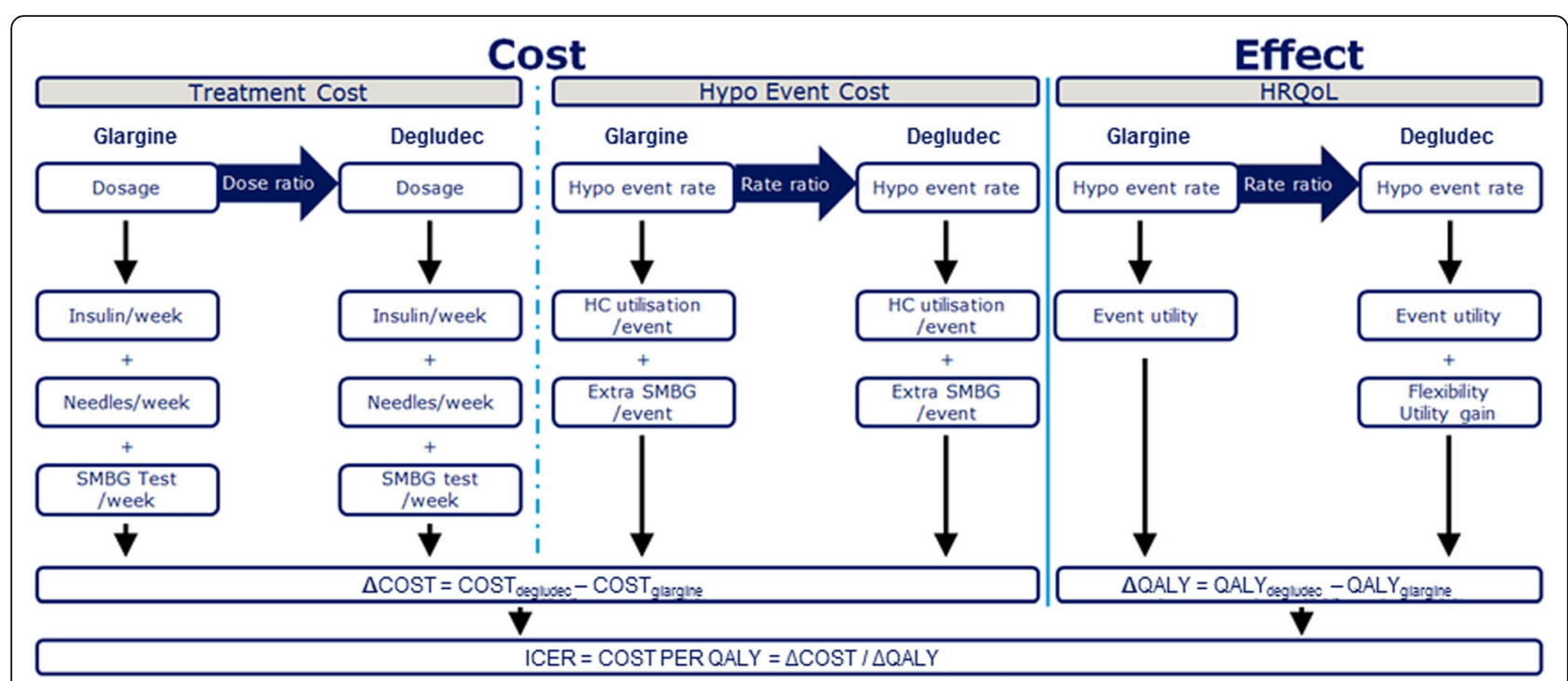

Fig. 1 Overview of cost-effectiveness model. Abbreviations: $\Delta$, change in; HC, healthcare, HRQoL, health-related quality of life; ICER, incremental cost-effectiveness ratio; QALY, quality-adjusted life year; SMBG, self-monitored blood glucose

setting and based on data from 1-year clinical studies, results are not only applicable for the cost-effectiveness of degludec in the first year of treatment. As the model can be replicated for subsequent years, the outcomes represent the average annual cost-effectiveness in a steady state. As the time horizon was 1 year, no discounting was applied.

\section{Clinical data}

\section{Insulin dose}

Units of insulin used per day for glargine U100 were taken from daily insulin doses used in clinical practice in Bulgaria [35]. The degludec/glargineU100 dose ratio was derived from a meta-analysis of insulin dose [27]. The degludec dose was derived from the dose ratio so that adjustment of covariate factors such as trial, treatment, anti-diabetic therapy at screening, age, sex, region, and baseline dose could be performed (Table 1). The insulin dose and dose ratio was solely used to calculate costs and was not included as a clinical outcome.

\section{Hypoglycaemia event rates}

Real-world non-severe hypoglycaemic event rates were derived from a large-scale multi-national survey of patients and physicians, and severe event rates were derived from a published observational study from the UK Hypoglycaemia Study Group (UKHSG) [36, 37]. Rates derived from observational studies more closely reflect real life event rates than clinical trial data, which can be biased in the selection of patients and the treatment setting. The base-case event rates in the glargine U100 group were the real-world hypoglycaemic event rates. Event rates for the degludec group were calculated using the degludec/glargine U100 hypoglycaemia rate ratios derived from a meta-analysis of hypoglycaemia which are adjusted for trial, type of diabetes, treatment, anti-

Table 1 Basal and bolus insulin use

\begin{tabular}{|c|c|c|c|}
\hline Treatment group & Observed glargine U100 (units/day) & Dose ratio (degludec/glargine U100) & Calculated degludec (units/day) \\
\hline $\mathrm{T1DM}_{\mathrm{B} / \mathrm{B} \text {, total dose }}$ & & $0.88^{*}$ & \\
\hline Basal insulin & 28.11 & $0.87^{*}$ & 24.46 \\
\hline Bolus insulin & 37.13 & $0.88^{*}$ & 32.67 \\
\hline T2DM & & $0.90^{*}$ & \\
\hline Basal insulin & 28.11 & $0.90^{*}$ & 25.30 \\
\hline Bolus insulin & Not relevant & Not relevant & Not relevant \\
\hline $\mathrm{T}_{2} \mathrm{DM}_{\mathrm{B} / \mathrm{B}}$, total dose & & Not significant & \\
\hline Basal insulin & 28.11 & $1.08^{*}$ & 30.36 \\
\hline Bolus insulin & 37.13 & Not significant & 37.13 \\
\hline
\end{tabular}

Abbreviations: B/B Basal-bolus, BOT Basal oral therapy, T1DM Type 1 diabetes mellitus, T2DM Type 2 diabetes mellitus

* $p<0.05$; NS Non-significant; in the case of non-significant results, a relative rate of one was used in the calculation 
diabetic therapy at screening, sex, region and age [27]. Only significant results were used for the calculation; in case of non-significant results, a rate ratio of one was used in the calculation (Table 2).

\section{Perspective}

All costs and resources used were estimated from a healthcare payer perspective of the Bulgarian NHIF.

\section{Data used in the model \\ Direct treatment costs}

The cost of insulin was calculated based on the pharmacy selling price (pharmacy purchase price, including VAT) in 2018, in BGN. The cost of needles and selfmonitoring of blood glucose (SMBG) tests are not reimbursed by NHIF and are paid out of pocket by patients.

\section{Cost of Hypoglycaemia}

The methods used to derive hypoglycaemia cost (summarised in Table 3) have been reported previously [34]. It was assumed that the cost of treating a severe or nonsevere hypoglycaemic event (diurnal and nocturnal) was similar regardless of whether the event was experienced by patients with T1DM, T2DM $\mathrm{BOT}_{\mathrm{T}}$ or $\mathrm{T} 2 \mathrm{DM}_{\mathrm{B} / \mathrm{B}}$.

\section{Utility data}

The methods used to derive utility data have been reported previously [34].

\section{Sensitivity analyses}

One-way and probabilistic sensitivity analyses were conducted to assess the impact of varying key assumptions and outcomes used in the base case analysis. (Table 4).

\section{Results}

\section{Costs}

The total costs for the three treatment groups are presented in Table 5. In T1DM, the total costs were estimated to be 3143.28 BGN per patient per year in the degludec group and 3073.92 BGN per patient per year for glargine U100, with approximately $40 \%$ of costs attributable to insulin and the remainder primarily due to severe hypoglycaemia. Total costs were 69.37 BGN higher (2.3\% higher) in the degludec group than the glargine U100 group, which is due to the increased insulin costs with degludec, partially offset (47.19 BGN) by lower costs of hypoglycaemia due to a significantly lower rate of non-severe nocturnal hypoglycaemia versus glargine U100.

In $\mathrm{T}_{2} \mathrm{DM}_{\mathrm{BOT}}$, the total costs per patient per year were $1.6 \%$ higher in the degludec group (1101.32 BGN) versus the glargine U100 group (1083.97 BGN). The incremental costs were mainly driven by the increased cost of insulin, partially offset by lower costs of hypoglycaemia in the degludec group. Lower costs of hypoglycaemia were driven by significant reductions in the number of nonsevere nocturnal and severe hypoglycaemic events in the degludec group versus glargine U100.

Table 2 Calculation of hypoglycaemia event rates

\begin{tabular}{|c|c|c|c|}
\hline & \multicolumn{2}{|c|}{ Non-severe hypoglycaemia } & \multirow[t]{2}{*}{ Severe hypoglycaemia } \\
\hline & Daytime & Nocturnal & \\
\hline \multicolumn{4}{|l|}{ T1DM } \\
\hline Total events/patient/year for glargine $U 100^{a}$ & 30.42 & 8.52 & 3.20 \\
\hline $\begin{array}{l}\text { Degludec/glargine U100 hypoglycaemic event } \\
\text { rate ratiob }\end{array}$ & Not Significant & $0.83^{*}$ & Not significant \\
\hline Calculated degludec hypoglycaemic event rate & 30.42 & 7.07 & 3.20 \\
\hline \multicolumn{4}{|l|}{ T2DM } \\
\hline Total events/patient/year for glargine $\cup 100^{\mathrm{a}}$ & 23.12 & 13.38 & 0.10 \\
\hline $\begin{array}{l}\text { Degludec/glargine U100 hypoglycaemic event } \\
\text { rate ratiob }\end{array}$ & Not significant & $0.64^{*}$ & $0.14^{*}$ \\
\hline Calculated degludec hypoglycaemic event rate & 23.11 & 8.57 & 0.01 \\
\hline \multicolumn{4}{|l|}{$\mathrm{T} 2 \mathrm{DM}_{\mathrm{B} / \mathrm{B}}$} \\
\hline Total events/patient/year for glargine $U 100^{\mathrm{a}}$ & 30.42 & 8.52 & 0.70 \\
\hline $\begin{array}{l}\text { Degludec/glargine U100 hypoglycaemic event } \\
\text { rate ratiob }\end{array}$ & $0.83^{*}$ & $0.75^{*}$ & Not significant \\
\hline Calculated degludec hypoglycaemic event rate & 25.25 & 6.39 & 0.70 \\
\hline
\end{tabular}

Abbreviations: B/B Basal-bolus, BOT Basal oral therapy, T1DM Type 1 diabetes mellitus, T2DM Type 2 diabetes mellitus.

* $p<0.05$; NS Non-significant; in the case of non-significant results, a relative rate of one was used in the calculation

a Taken from Brod et al. [37] and UK Hypoglycaemia Study Group [36]

b Taken from Vora et al. [27] 
Table 3 Total costs of an average severe/non-severe hypoglycaemia event

\begin{tabular}{lclc}
\hline & \multicolumn{3}{l}{$\begin{array}{l}\text { Cost per hypoglycaemic event in } \\
\text { patients with T1DM, T2DM }\end{array}$} \\
\cline { 2 - 4 } & $\begin{array}{l}\text { Non-severe } \\
\text { daytime }\end{array}$ & $\begin{array}{l}\text { Non-severe } \\
\text { nocturnal }\end{array}$ & Severe \\
\hline TOTAL (BGN)/event (2014) & 0.66 & 33.60 & 514.36 \\
TOTAL (BGN)/event (inflated & 0.65 & 33.19 & 508.10
\end{tabular}
to 2018)

Abbreviations: $B / B$ Basal-bolus, BGN Bulgarian LEV, BOT Basal oral therapy, T1DM Type 1 diabetes mellitus, T2DM Type 2 diabetes mellitus

In the $\mathrm{T} 2 \mathrm{DM}_{\mathrm{B} / \mathrm{B}}$ group, the total costs per person per year were 304.21 BGN (16.4\%) higher in the degludec group (2156.67 BGN) versus the glargine U100 group (1852.47 BGN). The incremental costs with degludec were caused by increased cost of insulin which were partially offset by lower costs of non-severe hypoglycaemia. In the clinical trials, the dose of basal insulin in the degludec treatment arm was higher than in the glargine U100 arm [27] which drives the higher incremental costs in this group.

\section{Incremental cost-effectiveness}

The incremental costs per QALY gained with degludec versus glargine U100 was estimated at 4499 BGN, 399 $\mathrm{BGN}$ and $7365 \mathrm{BGN}$ in T1DM, T2DM $\mathrm{BOT}_{\mathrm{T}}$ and $\mathrm{T}_{2} \mathrm{DM}_{\mathrm{B} / \mathrm{B}}$, respectively. In all three settings, degludec was highly cost-effective versus glargine U100 with the ICER values falling considerably below the costeffectiveness threshold assumed for Bulgaria (39,619 BGN) (Table 5).

\section{Sensitivity analysis}

One-way sensitivity analyses demonstrate that the results are robust and largely insensitive to variations in input parameters (Additional file 1: Table S1-Table S3). The parameter with most influence on the ICER was the rate of hypoglycaemia. In T1DM, degludec remained highly cost-effective versus glargine $\mathrm{U} 100$ in all scenarios tested. The ICERs ranged between 45 and 19,781 BGN/ QALY gained, with hypoglycaemic event rates having most influence on the ICER. When the number of nonsevere and severe hypoglycaemic events was increased to those reported by Ericsson et al. [38], the ICER decreased to 45 BGN/QALY gained. Conversely, when the lower hypoglycaemic event rates reported in clinical trials $[27,28]$ were used, the ICER increased to $5472 \mathrm{BGN} /$ QALY gained. Assuming no difference in the number of hypoglycaemic events between degludec and glargine U100 had the greatest effect on cost-effectiveness, increasing the ICER to 19,781 BGN/QALY gained. However, even in this scenario, degludec remained costeffective vs glargine U100.

In $\mathrm{T}_{2} \mathrm{DM}_{\mathrm{BOT}}$, the favourable cost-effectiveness results were invariant to changes in most of the input parameters tested. ICERs ranged between 32 BGN/QALY and 36,739 BGN/QALY gained. Using a lower number of hypoglycaemic events as reported in the clinical trials $[27,28]$, resulted in an increase in the ICER to 24,817 BGN/QALY gained but degludec remained cost-effective versus glargine U100 in this scenario. Conversely, using higher rates for severe hypoglycaemic events reported by Ericsson et al. [38], degludec became dominant versus glargine U100. Assuming no difference in hypoglycaemic event rates between degludec and glargine U100 had the greatest impact on the ICER, which increased to 36,739 BGN/QALY gained.

In $\mathrm{T}_{2} \mathrm{DM}_{\mathrm{B} / \mathrm{B}}$, the ICER was stable to reasonable variations in input parameters and was below the commonly accepted threshold for cost-effectiveness in almost all scenarios tested. The ICER increased when lower nonsevere hypoglycaemic event rates were assumed (ICER 8141 BGN/QALY gained) and when assuming no difference in the non-severe hypoglycaemic event rates between degludec and glargine U100 (ICER 13,826-15,236

Table 4 Sensitivity analyses conducted

\begin{tabular}{|c|c|c|}
\hline Parameter & Base case & Sensitivity analysis \\
\hline Time horizon & 1 year & The time horizon was increased to 5 years. \\
\hline Hypoglycaemia rates & $\begin{array}{l}\text { Published literature: } \\
\text { Brod et al. [37] } \\
\text { UK Hypoglycaemia Study Group [36] } \\
\text { Vora et al. [27] }\end{array}$ & $\begin{array}{l}\text { Additional published event rates }[27,28,38,39] \text { were investigated, } \\
\text { including those reported in the clinical trial programme. }\end{array}$ \\
\hline $\begin{array}{l}\text { Mortality incidence after } \\
\text { severe hypoglycaemia }\end{array}$ & $1.12 \%$ mortality risk & The mortality risk was decreased to zero. \\
\hline Cost of hypoglycaemia & Derived from clinical trial programme [40] & Healthcare costs were increased and decreased by $10 \%$. \\
\hline Insulin dose & $\begin{array}{l}\text { Published literature: } \\
\text { Vora et al. [27] } \\
\text { Doneva et al. [35] }\end{array}$ & $\begin{array}{l}\text { A sensitivity analysis was conducted assuming no difference in insulin } \\
\text { dose between the treatments. }\end{array}$ \\
\hline Flexible dosing utility & 0.006 (Boye et al. [41]) & $\begin{array}{l}\text { Several sensitivity analyses were conducted to assess the impact of flexible } \\
\text { dosing with degludec: one using an alternative utility value for flexible dosing } \\
(0.0130 \text { [42]); one where only } 50 \% \text { of patients gained a utility benefit of flexible } \\
\text { dosing; and one where there was no utility gain from dosing flexibility. }\end{array}$ \\
\hline
\end{tabular}


Table 5 Total cost per patient per year and incremental cost-effectiveness

\begin{tabular}{|c|c|c|c|c|c|c|c|c|c|}
\hline & \multicolumn{3}{|l|}{ T1DM } & \multicolumn{3}{|l|}{ T2DM } & \multicolumn{3}{|l|}{$\mathrm{T}_{2} \mathrm{DM}_{\mathrm{B} / \mathrm{B}}$} \\
\hline & $\begin{array}{l}\text { Degludec } \\
\text { (BGN/year) }\end{array}$ & $\begin{array}{l}\text { Glargine U100 } \\
\text { (BGN/year) }\end{array}$ & $\begin{array}{l}\text { Incremental } \\
\text { cost (BGN/year) }\end{array}$ & $\begin{array}{l}\text { Degludec } \\
\text { (BGN/year) }\end{array}$ & $\begin{array}{l}\text { Glargine U100 } \\
\text { (BGN/year) }\end{array}$ & $\begin{array}{l}\text { Incremental cost } \\
\text { (BGN/year) }\end{array}$ & $\begin{array}{l}\text { Degludec } \\
\text { (BGN/year) }\end{array}$ & $\begin{array}{l}\text { Glargine } \\
\text { U100 } \\
\text { (BGN/year) }\end{array}$ & $\begin{array}{l}\text { Incremental } \\
\text { cost (BGN/year) }\end{array}$ \\
\hline Insulin & 1296.67 & 1180.11 & 116.56 & 794.93 & 574.23 & 220.70 & 1574.88 & 1196.94 & 377.95 \\
\hline $\begin{array}{l}\text { Hypoglycaemia } \\
\text { events }\end{array}$ & 1846.61 & 1893.80 & -47.19 & 306.40 & 509.74 & -203.34 & 581.79 & 655.53 & -73.74 \\
\hline $\begin{array}{l}\text { Non-severe } \\
\text { daytime events }\end{array}$ & 19.42 & 19.42 & 0.00 & 15.02 & 15.02 & 0.00 & 16.35 & 19.69 & -3.35 \\
\hline $\begin{array}{l}\text { Non-severe } \\
\text { nocturnal events }\end{array}$ & 230.41 & 277.60 & -47.19 & 284.26 & 443.94 & -159.68 & 211.17 & 281.56 & -70.39 \\
\hline Severe events & 1596.78 & 1596.78 & 0.00 & 7.11 & 50.78 & -43.67 & 354.28 & 354.28 & 0.00 \\
\hline Total costs & 3143.28 & 3073.92 & 69.37 & 1101.32 & 1083.97 & 17.35 & 2156.67 & 1852.47 & 304.21 \\
\hline QALYS & 0.5722 & 0.5568 & 0.0154 & 0.7490 & 0.7055 & 0.0435 & 0.6893 & 0.6480 & 0.0413 \\
\hline $\begin{array}{l}\text { ICER (cost/ } \\
\text { QALY) }\end{array}$ & 4498.68 & & & 399.11 & & & 7365.22 & & \\
\hline
\end{tabular}

Abbreviations: $B / B$ Basal-bolus, BGN Bulgarian Lev, BOT Basal oral therapy, ICER Incremental cost-effectiveness ratio, QALY Quality-adjusted life years, T1DM Type 1 diabetes mellitus, T2DM Type 2 diabetes mellitus

BGN/QALY gained). The ICER exceeded the costeffectiveness threshold when no difference in the hypoglycaemia rate ratios was assumed (63,239 BGN/ QALY).

\section{Probabilistic sensitivity analysis}

To account for the uncertainty in the results caused by variation in data inputs, probabilistic sensitivity analyses were conducted. The cost-effectiveness acceptability curves demonstrated that, at a willingness-to-pay threshold of 39, 619 BGN/QALY, the probability of degludec being costeffective versus glargine U100 was $60.0 \%$ in T1DM, $99.4 \%$ in $\mathrm{T}_{2} \mathrm{DM}_{\mathrm{BOT}}$ and $91.3 \%$ in $\mathrm{T} 2 \mathrm{DM}_{\mathrm{B} / \mathrm{B}}$ (Fig. 2).

\section{Discussion}

There are limited data on the cost-effectiveness of insulin treatments in Bulgaria. The number of insulin treatment options continues to increase, and decision making based on economic evidence is essential to optimise health outcomes while effectively managing limited budgets.

In this simple, short-term cost-effectiveness analysis, degludec was demonstrated to be cost-effective versus biosimilar glargine U100 in people with T1DM (ICER 4498.68 BGN), T2DM ${ }_{\text {BOT }}$ (ICER 399.11 BGN) and $\mathrm{T}_{2} \mathrm{DM}_{\mathrm{B} / \mathrm{B}}$ (ICER 7365.22 BGN). Although insulin costs with degludec were higher than with glargine U100, there is a reduction in the number of hypoglycaemic events with degludec in all three patient groups, which partially offsets the higher drug costs.

Cost-effectiveness analyses usually model the longterm impact of diabetes interventions on disease-related complications as a function of the differences in glycaemic control. However the data used in this model were derived from treat-to-target trials and glycaemic control was similar across both arms, thus the use of a long-term model based on differences in $\mathrm{HbA}_{1 \mathrm{c}}$ was not appropriate. Therefore, this simple, transparent shortterm model focuses on other important aspects associated with insulin therapy, including hypoglycaemia and insulin dosing. Although this model only reflects a 1year time horizon, it not only represents the costeffectiveness of degludec vs glargine U100 within the first year of treatment, but it can also be replicated for subsequent years, representing annual cost-effectiveness. This is supported by the insensitivity of the ICER to changes in the time horizon in the sensitivity analyses. The model has previously been used to evaluate the cost-effectiveness of degludec versus glargine U100 in patients with T1DM and T2DM in different settings [33, 34, 38, 43-45]. In the United Kingdom (UK) and Denmark, degludec was found dominant versus glargine U100 in T1DM and T2DM ${ }_{\mathrm{BOT}}$ and highly cost-effective in $\mathrm{T}_{2} \mathrm{DM}_{\mathrm{B} / \mathrm{B}}[33,43]$. Similarly, in Serbia and Sweden, degludec was cost-effective versus glargine U100 in all three patient groups [34, 38]. These results are consistent with those observed in the current study.

Hypoglycaemia can have a major impact on patient's quality of life and lead to significant psychological and physical morbidity and in severe cases death [46, 47]. Additionally, people with recurrent hypoglycaemic episodes are at risk of developing impaired awareness of hypoglycaemia which can cause patients to miss early symptoms and treat hypoglycaemia, increasing the risk of severe hypoglycaemic events [48]. A recent real world multi-national, noninterventional study assessed the prevalence of hypoglycaemia worldwide, including Bulgaria. In Eastern Europe the estimated overall annual rate of hypoglycaemic events was 66.9 per person per year in T1DM and 23.7 per 

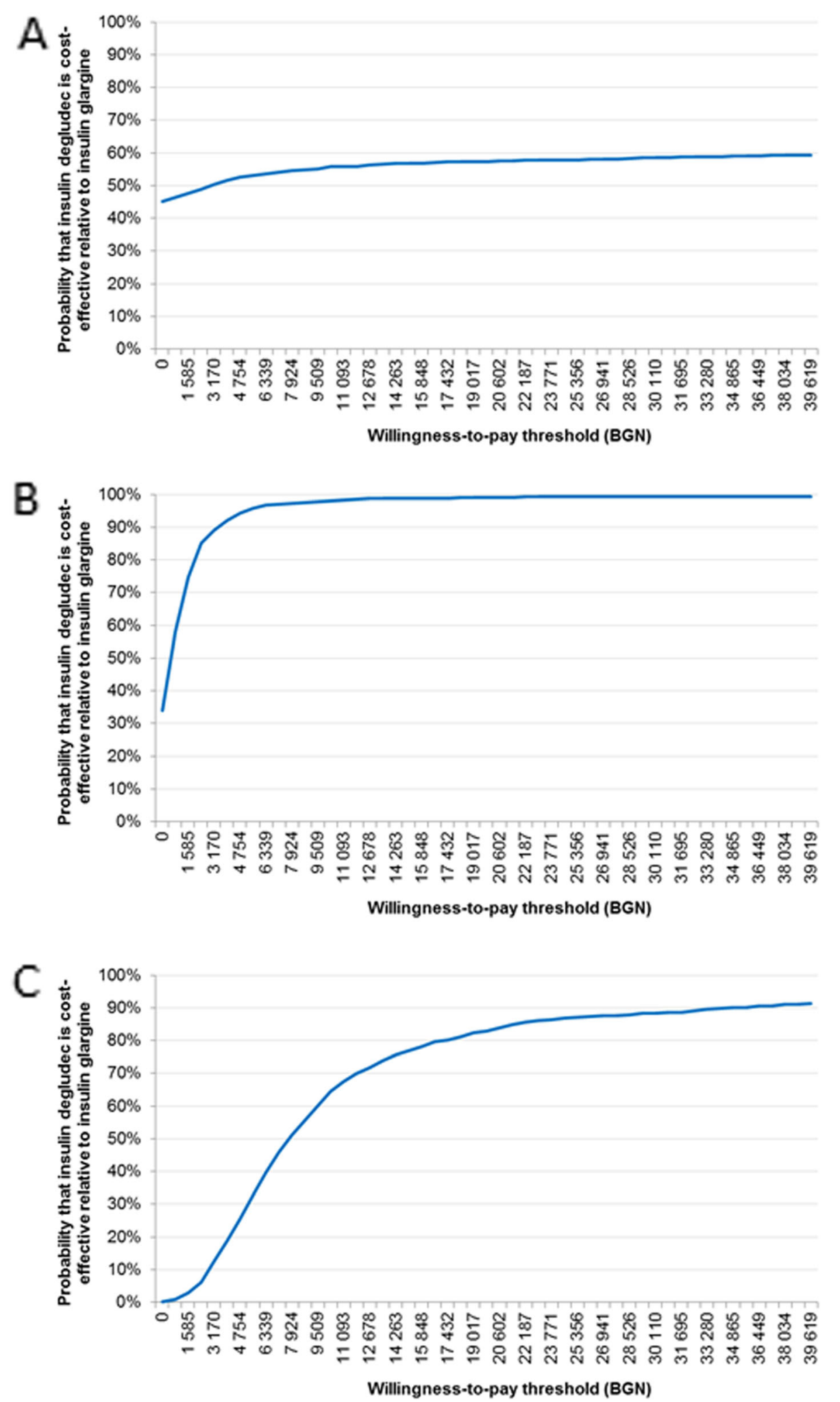

Fig. 2 Probabilistic sensitivity analyses acceptability curves 
person per year in T2DM [49]. The prevalence of nocturnal and severe hypoglycaemia were 9.8 and 4.5 per person per year in T1DM and 4.0 and 2.2 per person per year in T2DM. The nocturnal hypoglycaemic event rates in T1DM and severe events in T1DM and T2DM in Bulgaria are higher than those used in this model which, based on the impact of hypoglycaemic event rates demonstrated in the sensitivity analyses, suggests that degludec may be even more cost-effective in real world clinical practice in Bulgaria.

The real-world cost effectiveness of switching patients with T1DM from other basal insulins (glargine U100, insulin detemir and NPH insulin) to degludec has been investigated using the IQVIA CORE diabetes model from the perspective of the United Kingdom and Sweden [30, 50]. The CORE diabetes model is a lifetime Markov model predicting diabetes complications over time in patient populations representative of clinical practice and calculates the resulting economic impact. From both the UK and Swedish perspective, degludec was dominant versus other basal insulins, which was mainly driven by the significant reduction in $\mathrm{HbA}_{1 \mathrm{c}}$ and lower rates of hypoglycaemia with degludec $[30,50]$.

The initiation and intensification of insulin regimens is often hampered by hypoglycaemia and the fear of hypoglycaemia [51]. As a result of fear of hypoglycaemia, approximately $52 \%$ of people with T1DM and $41 \%$ of people with T2DM reduce their insulin dose following a hypoglycaemic event [52]. This compromises glycaemic control and puts patients at risk of serious long-term complications, such as cardiovascular disease, renal disease, retinopathy, neuropathy and amputations [53]. The unique pharmacological profile of degludec with a flat and stable action profile is associated with lower rates of hypoglycaemia [20, 22]. In phase 3 a clinical trials comparing degludec with glargine U100, degludec demonstrated equivalent reductions in $\mathrm{HbA}_{1 \mathrm{c}}$ with significantly lower rates of hypoglycaemia. In T1DM, degludec was associated with a $17 \%$ lower rate of non-severe nocturnal events, while in $\mathrm{T}_{2} \mathrm{DM}_{\mathrm{BOT}}$ and $\mathrm{T}_{2} \mathrm{DM}_{\mathrm{B} / \mathrm{B}}$, rates of nonsevere nocturnal hypoglycaemia were decreased by 36 and $25 \%$, respectively [27]. Additionally, the rate of nonsevere daytime events was $17 \%$ lower with degludec in $\mathrm{T}_{2} \mathrm{DM}_{\mathrm{B} / \mathrm{B}}$, and the rate of severe event hypoglycaemia was $86 \%$ lower in $\mathrm{T}_{2} \mathrm{DM}_{\mathrm{BOT}}[27,28]$.

In the SWITCH 1 and SWITCH 2 trials (phase 3b), degludec achieved equivalent reductions in $\mathrm{HbA}_{1 \mathrm{c}}$ with a significantly lower rate of overall symptomatic and severe hypoglycaemia versus glargine U100 in people with T1DM and T2DM with an increased risk of hypoglycaemia $[54,55]$. These trials are more representative of patients in regular clinical practice than the phase 3a clinical trials, which excluded patients with recurrent hypoglycaemia. Data from SWITCH trials have recently been used to demonstrate that degludec is a cost-effective alternative to glargine U100 in the UK [56]. Furthermore, the hypoglycaemia benefit of degludec has been confirmed in real-world studies which demonstrate that switching to degludec from other basal insulin regimens is associated with significantly improved glycaemic control and a reduction in the rate of non-severe and severe hypoglycaemic events in T1DM and T2DM $[29,30]$.

In Bulgaria, SMBG tests are not paid by the healthcare payer but are paid out-of-pocket by patients, and were therefore not considered in this analysis. Due to the long duration of action with a flat and stable action profile and the lower day-to-day variability versus glargine U100, fewer SMBG tests are needed for titration and maintenance with degludec $[20,22,57]$. Fewer SMBG tests would be cost saving for the patient, although this was not assessed in the present analysis. The long and stable action profile of degludec also allows for flexibility of dosing time without compromising efficacy or risk of hypoglycaemia [25]. This flexible dosing option may provide an additional benefit especially for those people who have difficulties adhering to their treatment regimens (e.g. shift workers, frequent travellers, patients requiring help with insulin injections). Here, an estimate of the utility benefit of flexible dosing with degludec was included in the analysis and a utility gain of 0.006 derived from the study by Boye et al. [41] was applied for degludec. This can be considered a conservative estimate as a large time trade-off study identified a utility gain of 0.016 associated with flexible dosing of basal insulin and 0.013 vs fixed basal-bolus regimens [42].

It is important to acknowledge the limitations associated with the current analysis. With biosimilar glargine U100 being a relatively new-to-market insulin, no headto-head trial data are available comparing degludec vs biosimilar glargine U100 and the analysis was based on currently available data and plausible assumptions, and the results should be interpreted accordingly. The analysis used hypoglycaemic event rates derived from published economic analyses using this model [33]. This could have resulted in an underestimation of the costeffectiveness of degludec vs glargine U100 in Bulgaria, as a recent study suggests that rates of hypoglycaemia in real-world clinical practice in Bulgaria may be higher [49]. Additionally, the data used in this model to inform hypoglycaemia rate ratios originate from meta-analyses of phase 3 a clinical trials $[27,28]$ to increase the statistical power of the analyses and increase the reliability of the data, and assumes replication of such rates in clinical practice. Except for hypoglycaemia, adverse events are not considered in our analysis, as head-to-head clinical trials have shown that degludec and glargine have similar safety profiles [26]. Furthermore, the cardiovascular 
outcomes trial DEVOTE showed that insulin degludec was non-inferior to insulin glargine in terms of major adverse cardiovascular events [58]. The clinical trials which informed this analysis used a treat-to-target approach in which patients were titrated until glycaemic targets were reached. In clinical practice, glycaemic targets are often not met for a variety of reasons, including non-adherence, and missed follow-up appointments. However, sensitivity analyses demonstrate that the results are robust to a wide variation in parameters, supporting the validity of the results.

\section{Conclusion}

This short-term cost-effectiveness analysis demonstrates that degludec is a cost-effective alternative to biosimilar glargine U100 for patients with T1DM and T2DM in Bulgaria. Degludec could be of particular benefit to those patients suffering recurrent hypoglycaemia and those who require additional flexibility in the dosing of insulin.

\section{Supplementary information}

Supplementary information accompanies this paper at https://doi.org/10. 1186/s12902-019-0460-6.

Additional file 1: Table S1. Sensitivity analyses for T1DM, Table S2. Sensitivity analyses for T2DM $\mathrm{BOT}_{\mathrm{B}}$, Table S3. Sensitivity analyses for $\mathrm{T}_{2} \mathrm{DM}_{\mathrm{B} / \mathrm{B} \text {. }}$

\section{Abbreviations}

BGN: Bulgarian LEV; Cl: Confidence interval; DDD: Daily defined dose; GDP: Gross domestic product; HC: Healthcare; HRQoL: Health-related quality of life; ICER: Incremental cost-effectiveness ratio; NHIF: National Health Insurance Fund; NS: Non-significant; QALY: Quality-adjusted life year; SMBG: Self-monitored blood glucose; T1DM: Type 1 diabetes mellitus; T1DMB/B: T1DM using basal-bolus therapy; T2DM: Type 2 diabetes mellitus; T2DMB/B: T2DM using basal-bolus therapy; T2DMBOT: T2DM using basal-oral therapy; TTO: Time trade off

\section{Acknowledgements}

Medical Writing and Editorial Assistance.

The authors acknowledge medical writing and editorial support by Katrin Nather and Carrie Fidler of DRG Abacus.

\section{Authors' contributions}

MR and W contributed to design, execution and reporting of the analysis. AS and MM contributed to reporting and interpretation of the data. All authors have read and approved the manuscript.

\section{Funding}

The study itself, the writing of the manuscript, and the article processing charges were funded by Novo Nordisk. Novo Nordisk designed the model, which was adapted by MR and W, who contributed as authors as outlined in the author contributions. All authors had full access to all data in this study and take complete responsibility for the integrity of the data and accuracy of the data analysis.

\section{Availability of data and materials}

All data on which the conclusions of the manuscript are based are presented in the main paper or additional supporting files.

\section{Ethics approval and consent to participate}

This article does not contain any studies with human participants or animals performed by any of the authors.

\section{Competing interests}

Alexandra Savova and Manoela Manova have nothing to declare. Monika Russel-Szymczyk and Vasil Valov are employees of Novo Nordisk.

\section{Author details}

${ }^{1}$ Novo Nordisk Pharma Sp. z o.o, Warsaw, Poland. ${ }^{2}$ Novo Nordisk Pharma EAD, Sofia, Bulgaria. ${ }^{3}$ Faculty of Pharmacy, Medical University Sofia, Sofia, Bulgaria.

Received: 20 August 2019 Accepted: 22 November 2019

Published online: 03 December 2019

\section{References}

1. International Diabetes Federation (IDF). Diabetes atlas - 8th edition. Available at: http://www.diabetesatlas.org/.

2. American Diabetes Association. Economic costs of diabetes in the U.S. in 2012. Diabetes Care. 2013;36(4):1033-46.

3. Jonsson B. Revealing the cost of type II diabetes in Europe. Diabetologia. 2002;45(7):S5-12.

4. American Diabetes Association. Economic costs of diabetes in the U.S. in 2017. Diabetes Care. 2018;41(5):917-28.

5. Stratton IM, Adler Al, Neil HA, Matthews DR, Manley SE, Cull CA, et al. Association of glycaemia with macrovascular and microvascular complications of type 2 diabetes (UKPDS 35): prospective observational study. BMJ. 2000;321(7258):405-12.

6. The Diabetes Control and Complications Trial Research Group. The effect of intensive treatment of diabetes on the development and progression of long-term complications in insulin-dependent diabetes mellitus. The Diabetes Control and Complications Trial Research Group. N Engl J Med. 1993;329(14):977-86

7. Bulgarian Society of Endocrinology. Good clinical practice guidelines on diabetes mellitus. 2016.

8. Davies MJ, D'Alessio DA, Fradkin J, Kernan WN, Mathieu C, Mingrone G, et al. Management of hyperglycemia in type 2 diabetes, 2018. A consensus report by the American Diabetes Association (ADA) and the European Association for the Study of Diabetes (EASD). Diabetes Care. 2018:41(12): 2669-701.

9. Giugliano D, Maiorino MI, Bellastella G, Chiodini P, Ceriello A, Esposito K. Efficacy of insulin analogs in achieving the hemoglobin A1c target of $<7 \%$ in type 2 diabetes: meta-analysis of randomized controlled trials. Diabetes Care. 2011:34(2):510-7.

10. International Diabetes Federation (IDF) Clinical Guidelines Task Force. Global guideline for type 2 diabetes, 2012. Available at https://www.idf.org/elibrary/guidelines/79-global-guideline-for-type-2-diabetes

11. American Diabetes Association. Standards of medical care in diabetes-2018. Diabetes Care. 2018;41(Suppl 1):S1-S153.

12. Blak BT, Smith HT, Hards M, Curtis BH, Ivanyi T. Optimization of insulin therapy in patients with type 2 diabetes mellitus: beyond basal insulin. Diabet Med. 2012;29(7):e13-20

13. de Pablos-Velasco P, Parhofer KG, Bradley C, Eschwege E, Gonder-Frederick $L$, Maheux $P$, et al. Current level of glycaemic control and its associated factors in patients with type 2 diabetes across Europe: data from the PANORAMA study. Clin Endocrinol (Oxf). 2014;80(1):47-56.

14. Govan L, Wu O, Briggs A, Colhoun HM, Fischbacher CM, Leese GP, et al. Achieved levels of HbA1c and likelihood of hospital admission in people with type 1 diabetes in the Scottish population: a study from the Scottish Diabetes research network epidemiology group. Diabetes Care. 2011;34(9):1992-7.

15. NHS Health \& Social Care Information Centre. National Diabetes Audit 20112012; Report 1: Care Processes and Treatment Targets, Available at http://content. digital.nhs.uk/catalogue/PUB12421/nati-diab-audi-11-12-care-proc-rep.pdf.

16. Cokolic M, Lalic NM, Micic D, Mirosevic G, Klobucar Majanovic S, Lefterov IN, et al. Patterns of diabetes care in Slovenia, Croatia, Serbia, Bulgaria and Romania. Wien Klin Wochenschr. 2017;129(5):192-200,

17. Calvert MJ, McManus RJ, Freemantle N. Management of type 2 diabetes with multiple oral hypoglycaemic agents or insulin in primary care: retrospective cohort study. Br J Gen Pract. 2007;57(539):455-60.

18. Rubino A, McQuay $\amalg$, Gough SC, Kvasz M, Tennis P. Delayed initiation of subcutaneous insulin therapy after failure of oral glucose-lowering agents in patients with type 2 diabetes: a population-based analysis in the UK. Diabet Med. 2007;24(12):1412-8. 
19. Peyrot M, Rubin RR, Lauritzen T, Skovlund SE, Snoek FJ, Matthews DR, et al. Resistance to insulin therapy among patients and providers: results of the cross-national Diabetes attitudes, wishes, and needs (DAWN) study. Diabetes Care. 2005;28(11):2673-9.

20. Heise $T$, Nosek L, Bottcher SG, Hastrup H, Haahr H. Ultra-long-acting insulin degludec has a flat and stable glucose-lowering effect in type 2 diabetes. Diabetes Obes Metab. 2012;14(10):944-50.

21. Haahr $\mathrm{H}$, Heise T. A review of the pharmacological properties of insulin degludec and their clinical relevance. Clin Pharmacokinet. 2014;53(9):787800.

22. Heise T, Hermanski L, Nosek L, Feldman A, Rasmussen S, Haahr H. Insulin degludec: four times lower pharmacodynamic variability than insulin glargine under steady-state conditions in type 1 diabetes. Diabetes Obes Metab. 2012;14(9):859-64.

23. Heise T, Norskov M, Nosek L, Kaplan K, Famulla S, Haahr HL. Insulin degludec: lower day-to-day and within-day variability in pharmacodynamic response compared with insulin glargine $300 \mathrm{U} / \mathrm{mL}$ in type 1 diabetes. Diabetes Obes Metab. 2017;19(7):1032-9.

24. Heise T, Kaplan K, Haahr HL. Day-to-day and within-day variability in glucose-lowering effect between insulin Degludec and insulin Glargine (100 $\mathrm{U} / \mathrm{mL}$ and $300 \mathrm{U} / \mathrm{mL}$ ): a comparison across studies. J Diabetes Sci Technol. 2018;12(2):356-63.

25. European Medicines Agency. Tresiba ${ }^{\circledR}$ (insulin degludec) Summary of Product Characteristics. Available at: https://www.ema.europa.eu/ documents/product-information/tresiba-epar-product-information_en.pdf.

26. Wangnoo SK, Chowdhury S, Rao PV. Treating to target in type 2 diabetes: the BEGIN trial programme. J Assoc Physicians India. 2014;62(1 Suppl):21-6.

27. Vora J, Christensen T, Rana A, Bain SC. Insulin degludec versus insulin glargine in type 1 and type 2 diabetes mellitus: a meta-analysis of endpoints in phase 3a trials. Diab Therapy. 2014;5(2):435-46.

28. Ratner R, Gough SC, Mathieu C, Prato SD, Bode B, Mersebach H, et al. Hypoglycaemia risk with insulin Degludec compared with insulin Glargine in type 2 and type 1 Diabetes: a pre-planned meta-analysis of phase 3 trials. Diabetes Obes Metab. 2013;15(2):175-84.

29. Siegmund T, Tentolouris N, Knudsen ST, Lapolla A, Prager R, Phan TM, et al. A European, multicentre, retrospective, non-interventional study (EU-TREAT) of the effectiveness of insulin degludec after switching basal insulin in a population with type 1 or type 2 diabetes. Diabetes Obes Metab. 2018;20(3): 689-97.

30. Evans M, McEwan P, Foos V. Insulin degludec early clinical experience: does the promise from the clinical trials translate into clinical practice-a casebased evaluation. J Med Econ. 2015;18(2):96-105.

31. Sassi F. Calculating QALYs, comparing QALY and DALY calculations. Health Policy Plan. 2006;21(5):402-8.

32. Macroeconomics and health: investing in health for economic development. Report of the Commission on Macroeconomics and Health. Geneva: World Health Organization; 2001. Available from: http://apps.who. int/iris/bitstream/10665/42435/1/924154550X.pdf

33. Evans M, Chubb B, Gundgaard J. Cost-effectiveness of insulin degludec versus insulin glargine in adults with type 1 and type 2 diabetes mellitus. Diab Therapy. 2017;8(2):275-91.

34. Lalic N, Russel-Szymczyk M, Culic M, Tikkanen CK, Chubb B. Costeffectiveness of insulin Degludec versus insulin Glargine U100 in patients with type 1 and type 2 Diabetes mellitus in Serbia. Diab Therapy. 2018;9(3):1201-16.

35. Doneva M, Valov V, Borisova A-M, Tankova T, Savova A, Manova M, et al. Comparative Analysis of the Cost of Insulin Treated Patients in Bulgaria. Biotechnol Biotechnologic Equip. 2013;27(2):3748-52.

36. UK Hypoglycaemia Study Group. Risk of hypoglycaemia in types 1 and 2 diabetes: effects of treatment modalities and their duration. Diabetologia. 2007;50(6):1140-7.

37. Brod M, Rana A, Barnett AH. Impact of self-treated hypoglycaemia in type 2 diabetes: a multinational survey in patients and physicians. Curr Med Res Opin. 2012;28(12):1947-58.

38. Ericsson A, Pollock RF, Hunt B, Valentine WJ. Evaluation of the cost-utility of insulin degludec vs insulin glargine in Sweden. J Med Econ. 2013;16(12): 1442-52.

39. Ostenson CG, Geelhoed-Duijvestijn P, Lahtela J, Weitgasser R, Markert Jensen M, Pedersen-Bjergaard U. Self-reported non-severe hypoglycaemic events in Europe. Diabet Med. 2014;31(1):92-101.
40. Heller SR, Frier BM, Herslov ML, Gundgaard J, Gough SC. Severe hypoglycaemia in adults with insulin-treated diabetes: impact on healthcare resources. Diabet Med. 2016;33:471-7.

41. Boye KS, Matza LS, Walter KN, Van Brunt K, Palsgrove AC, Tynan A. Utilities and disutilities for attributes of injectable treatments for type 2 diabetes. Eur J Health Econ. 2011;12(3):219-30.

42. Evans M, Jensen HH, Bogelund M, Gundgaard J, Chubb B, Khunti K. Flexible insulin dosing improves health-related quality-of-life (HRQOL): a time tradeoff survey. J Med Econ. 2013;16(11):1357-65.

43. Pollock RF, Tikkanen CK. A short-term cost-utility analysis of insulin degludec versus insulin glargine U100 in patients with type 1 or type 2 diabetes in Denmark. J Med Econ. 2017;20(3):213-20.

44. Evans M, Wolden M, Gundgaard J, Chubb B, Christensen T. Costeffectiveness of insulin degludec compared with insulin glargine for patients with type 2 diabetes treated with basal insulin - from the UK health care cost perspective. Diabetes Obes Metab. 2014;16(4):366-75.

45. Evans M, Wolden M, Gundgaard J, Chubb B, Christensen T. Costeffectiveness of insulin degludec compared with insulin glargine in a basalbolus regimen in patients with type 1 diabetes mellitus in the UK. J Med Econ. 2015;18(1):56-68.

46. Frier BM. The economic costs of hypoglycaemia. Br J Diabetes Vasc Dis. 2011;11(Suppl 1):S10-S2.

47. Khunti K, Davies M, Majeed A, Thorsted BL, Wolden ML, Paul SK. Hypoglycemia and risk of cardiovascular disease and all-cause mortality in insulin-treated people with type 1 and type 2 diabetes: a cohort study. Diabetes Care. 2015;38(2):316-22.

48. Graveling AJ, Frier BM. Impaired awareness of hypoglycaemia: a review. Diabetes Metab. 2010;36(Suppl 3):S64-74.

49. Khunti K, Alsifri S, Aronson R, Cigrovski Berkovic M, Enters-Weijnen C, Forsen T, et al. Rates and predictors of hypoglycaemia in 27585 people from 24 countries with insulin-treated type 1 and type 2 diabetes: the global HAT study. Diabetes Obes Metab. 2016;18(9):907-15.

50. Landstedt-Hallin L, Gundgaard J, Ericsson A, Ellfors-Zetterlund S. Costeffectiveness of switching to insulin degludec from other basal insulins: evidence from Swedish real-world data. Curr Med Res Opin. 2017:33(4):64755

51. Peyrot M, Barnett AH, Meneghini LF, Schumm-Draeger PM. Insulin adherence behaviours and barriers in the multinational global attitudes of patients and physicians in insulin therapy study. Diabet Med. 2012;29(5): $682-9$.

52. Khunti K, Alsifri S, Aronson R, Cigrovski Berkovic M, Enters-Weijnen C, Forsen T, et al. Impact of hypoglycaemia on patient-reported outcomes from a global, 24-country study of 27,585 people with type 1 and insulin-treated type 2 diabetes. Diabetes Res Clin Pract. 2017;130:121-9.

53. Diabetes UK. Facts and stats 2016. Available at: https://www.diabetes.org.uk Documents/Position\%20statements/DiabetesUK_Facts_Stats_Oct16.pdf.

54. Lane W, Bailey TS, Gerety G, Gumprecht J, Philis-Tsimikas A, Hansen CT, et al. Effect of insulin Degludec vs insulin Glargine U100 on hypoglycemia in patients with type 1 Diabetes: the SWITCH 1 randomized clinical trial. JAMA. 2017:318(1):33-44.

55. Wysham C, Bhargava A, Chaykin L, de la Rosa R, Handelsman Y, Troelsen LN, et al. Effect of insulin Degludec vs insulin Glargine U100 on hypoglycemia in patients with type 2 Diabetes: the SWITCH 2 randomized clinical trial. JAMA. 2017;318(1):45-56.

56. Evans M, Mehta R, Gundgaard J, Chubb B. Cost-effectiveness of insulin degludec vs. insulin glargine U100 in type 1 and type 2 diabetes mellitus in a UK setting. Diab Therapy. 2018;9(5):1919-30.

57. Philis-Tsimikas A, Brod M, Niemeyer M, Ocampo Francisco AM, Rothman J. Insulin Degludec once-daily in type 2 Diabetes: simple or step-wise titration (BEGIN: once simple use). Adv Ther. 2013;30(6):607-22.

58. Marso SP, McGuire DK, Zinman B, Poulter NR, Emerson SS, Pieber TR, et al. Efficacy and safety of degludec versus glargine in type 2 diabetes. N Engl J Med. 2017;377(8):723-32

\section{Publisher's Note}

Springer Nature remains neutral with regard to jurisdictional claims in published maps and institutional affiliations. 